\title{
myc Family Oncogene Amplification in Tumor Cell Lines Established from Small Cell Lung Cancer Patients and Its Relationship to Clinical Status and Course
}

\author{
Bruce E. Johnson, Daniel C. Ihde, Robert W. Makuch,* Adi F. Gazdar, Desmond N. Carney, Herbert Oié, Edward Russell, \\ Marion M. Nau, and John D. Minna \\ National Cancer Institute-Navy Medical Oncology Branch, National Cancer Institute and Naval Hospital, Department of Medicine, \\ Uniformed Services, University of the Health Sciences, Bethesda, Maryland 20814; and *Division of Biostatistics, \\ Yale University School of Medicine, New Haven, Connecticut 06510
}

\begin{abstract}
44 small cell lung cancer cell lines established from 227 patients were studied for myc family DNA amplification (c-myc, $\mathrm{N}$-myc, and L-myc). Two of 19 lines (11\%) established from untreated patients' tumors had DNA amplification (one $\mathbf{N}$-myc and one $\mathbf{L}$ myc), compared with 11 of 25 (5 c-myc, $3 \mathrm{~N}$-myc, and $3 \mathrm{~L}$-myc) cell lines $(44 \%)$ established from relapsed patients' tumors $(P$ $=0.04)$. The 19 patients who had tumor cell lines established before chemotherapy treatment survived a median of 14 wk compared with 48 wk for the 123 extensive stage patients who did not have cell lines established $(P<0.001)$. Relapsed patients whose cell lines had c-myc DNA amplification survived a shorter period (median of 33 wk) than patients whose cell lines did not have c-myc amplification (median of 53 wk; $P=0.04$ ). We conclude that (a) myc family DNA amplification is more common in tumor cell lines established from treated than untreated patients' tumiors, and (b) c-myc amplification in treated patients' tumor cell lines is associated with shortened survival.
\end{abstract}

\section{Introduction}

The role of oncogene activation by amplification in the generation and progression of most human malignancies is poorly defined. $m y c$ family (c-myc, N-myc, and L-myc) DNA amplification has been described in a variety of cancer cell lines and tumor specimens. This includes c-myc DNA amplification, which has been previously reported in tumor cell lines established from patients with leukemia (1), colon cancer (2), breast cancer (3), gastric cancer (4), glioblastoma (5), non-small cell lung cancer (6), and small cell lung cancer $(6,7)$. N-myc, which shares DNA sequence homology with c-myc, is amplified in some tumors and tumor cell lines derived from neuroendocrine tissues, including neuroblastoma and retinoblastoma (8-12). N-myc amplification occurs in childhood neuroblastoma in $\sim 33 \%$ of patients' tumors and is associated with advanced stage disease (10) as well as more rapid tumor progression (11). Small cell lung cancer cell lines and tumors have also been shown to be amplified for the $\mathrm{N}-m y c$ oncogene (13). In addition, L-myc, a new oncogene sharing DNA sequence homology with both c-

Opinions or assertions contained herein are the private views of the authors and are not to be construed as official or as reflecting the views of the Department of the Navy or the Department of Defense.

Address reprint requests to Bruce E. Johnson, M.D., NCI-Navy Medical Oncology Branch, Building 8, Room 5108, Naval Hospital, Bethesda, MD 20814.

Received for publication 20 August 1986 and in revised form 23 January 1987.

The Journal of Clinical Investigation, Inc.

Volume 79, June 1987, 1629-1634 $m y c$ and $\mathrm{N}-m y c$, has been found to be amplified and expressed in small cell lung cancer cell lines and tumors (14). However, the relationship between the clinical status and course of a cohort of patients and myc family DNA amplification in their tumor cell lines remains to be defined.

In addition, little information is available concerning whether the biology of human tumor cell lines is representative of the broad spectrum of human tumor biology. In childhood neuroblastoma where some data exists, nearly all cell lines arè amplified for the oncogene, $\mathrm{N}-m y c(8,9)$, whereas only one third of the actual tumor specimens have DNA amplification of $\mathrm{N}-m y c(10)$. Neuroblastoma patients whose tumors have DNA amplification of $\mathrm{N}-m y c$ are more likely to present with advanced-stage disease and have a more rapid tumor progression $(10,11)$. This suggests that the neuroblastoma cell lines, nearly all of which have $\mathrm{N}$ myc amplification, may not be typical of the biologic characteristics of all childhood neuroblastomas.

44 patients with small cell lung cancer who were staged and treated on prospective therapeutic clinical trials at the National Cancer Institute-Navy Medical Oncology Branch also had tumor cell lines established $(15,16)$. We determined the DNA copy number of $c-m y c, \mathrm{~N}-m y c, \mathrm{~L}-m y c$ in these tumor lines and correlated this data with the clinical information and outcome. This large number of small cell lung cancer cell lines with complete clinical information on the patients from whom the cell lines were established allowed an evaluation of the relationship between oncogene amplification and the patients' clinical characteristics and course.

\section{Methods}

We treated 227 newly diagnosed patients with histologically confirmed small cell lung cancer from 1977 through July of 1984 in a series of intramural National Cancer Institute (NCI) ${ }^{1}$ therapeutic clinical trials. Following an evaluation previously described, patients were assigned a Zubrod performance status (17) and designated as having either limitedor extensive-stage disease (18). All patients were treated with combination chemotherapy with or without chest or cranial irradiation.

The 227 patients underwent diagnostic and therapeutic procedures (bone marrow aspirate and biopsy, thoracentesis, and surgical resection of tumor masses) during staging and treatment from which tumor tissue was obtained. When adequate tumor tissue was available after the diagnostic needs of pathology were fulfilled, the specimens were processed and used to attempt to establish cell lines as previously described (15, 16). After 3-6 mo of continued growth in cell culture media, the tumor cells that could grow at a relatively low density free of stromal cell contamination and could be routinely maintained in a variety of media, including RPMI 1640 plus $10 \%$ fetal bovine serum, were considered established cell lines (15). 44 tumor cell lines were established from the

1. Abbreviations used in this paper: DM, double-minute chromosome; HSR, homogenous staining region; NCI, National Cancer Institute. 
227 small cell lung cancer patients. All patients from whom these cell lines were established were identified and the clinical course was reviewed. The age, sex, stage of disease, Zubrod performance status, sites of extensive disease, date of initial chemotherapy, number of drugs administered, duration of therapy, date cell lines were started, site from which the cell line was started, and the date of death were noted.

The c-myc, $\mathrm{N}-m y c$, and L-myc DNA copy number in the 44 cell lines was determined by harvesting the cells during log phase growth, preparing DNA (19), digesting the DNA with the Eco RI restriction endonuclease, electrophoresing the DNA on $0.8 \%$ agarose gels, and transferring the DNA to nitrocellulose filters by the method of Southern (20). The DNA was hybridized to ${ }^{32}$ P-labeled purified DNA fragments of c-myc, a Cla I-Eco RI fragment containing the third exon (21); N$m y c$, an Eco RI-Bam HI fragment containing the second exon (8); and L-myc, a Sma I-Eco RI fragment $3^{\prime}$ to the gene containing the homology region to the second exon of c-myc and $\mathrm{N}-m y c$ (14). The filters were washed as previously described (6) and were exposed to X-ray film. NCI small cell lung cancer cell lines $\mathrm{H} 146$ and $\mathrm{H} 187$ were used as controls for a single copy of c-myc, N-myc, and L-myc. The c-myc, N-myc, and L-myc copy number of the amplified cell lines was determined by densitometry relative to the single copy control cell lines. The variations in the amount of DNA loaded per lane were adjusted by standardizing the c-myc, N-myc, and L-myc signal to the signal made from a single copy oxytocin gene, a 10-kb Eco RI fragment (22). The copy number of the $m y c$ genes was considered to be amplified if the densitometry readings were fourfold greater than the single copy gene controls.

The survival time of the patients was calculated from the date of initial chemotherapy; complete follow-up was available on all patients. Contingency tables were analyzed using the Pearson chi-square statistic, adjusted for continuity where appropriate. Continuous data were compared using the Wilcoxon two-sample test. Time-to-failure curves were calculated using the Kaplan-Meier method (23). The entire curves were compared one to another using Gehan's generalized Wilcoxon statistic (24). All cited $P$ values correspond to two-sided tests.

\section{Results}

DNA from 13 of the 44 small cell lung cancer cell lines was amplified for one of the $m y c$ family oncogenes, 5 for c-myc, 4 for N-myc, and 4 for L-myc (Figs. 1-3). The rearranged amplified c-myc bands in three cell lines (Fig. 1; H60, H82, and H524) have been previously observed and all these cell lines express a normal size 2.3-kb c-myc mRNA $(6,16)$. The rearranged amplified N-myc band in H526 (Fig. 2) has been previously reported and a novel-sized 1.8-kb N-myc mRNA is detected in the cell line (13). Karyotype information was available on 14 of the 44 cell lines studied (25). Homogeneous staining regions (HSR) or double-minute chromosomes (DM) were found in three of the four $m y c$ family amplified cell lines studied. The c-myc amplified cell lines $\mathrm{H} 60$ and $\mathrm{H} 82$ had DMs and an HSR, respectively. The $\mathrm{N}-m y c$ amplified cell line $\mathrm{H} 69$ had DMs. H211, a c-myc amplified cell line, and all 10 other nonamplified cell lines studied did not have either DMs or HSRs.

The incidence of myc family DNA amplification was related to the treatment status of the patient at the time the tumor cell line was established (Table I). DNA from 19 tumor cell lines established from untreated small cell lung cancer patients was studied. Only two lines (11\%) had DNA amplification (one $\mathrm{N}$ $m y c$ and one L-myc). 25 small cell lung cancer cell lines were established from patients whose tumor was progressing after an initial regression following the administration of chemotherapy. DNA from 11 of these 25 cell lines (44\%) was amplified for one of the $m y c$ family oncogenes ( 5 for c-myc, 3 for N-myc, and 3 for L-myc). Thus $m y c$ family DNA amplification was observed more often in cell lines established from relapsed patients than

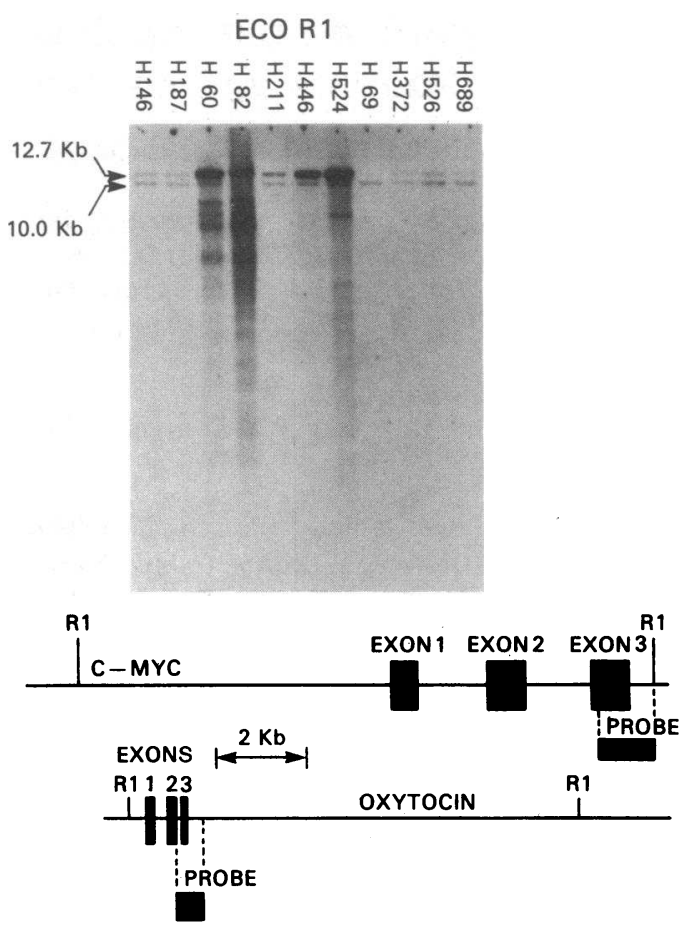

Figure 1. Autoradiograms of DNA from small cell lung cancer cell lines hybridized to a c-myc and oxytocin probe. $10 \mu \mathrm{g}$ of DNA prepared from small cell lung cancer cell lines was digested with Eco RI restriction endonuclease, Southern blots prepared and hybridized to third exon probes of c-myc and oxytocin and exposed to x-ray film. A schematic representation of the normal germline human c-myc and oxytocin genes are depicted at bottom. Numbered solid boxes represent their respective mRNA coding exons and vertical lines represent restriction endonuclease sites. DNA from five cell lines has multiple copies of the normal size 12.7-kb Eco RI c-myc fragment (H60, H82, $\mathrm{H} 211, \mathrm{H} 446$, and H524). Additional bands appear where the c-myc gene has been rearranged. All five cell lines are from patients who had been previously treated. The single copy $10-\mathrm{kb}$ Eco RI oxytocin fragment appears below the c-myc fragment. All but $\mathrm{H} 211$ have more than 10-fold amplification of c-myc.

from untreated patients $(P=0.04)$. In this series of tumor cell lines; c-myc DNA amplification was seen only in cell lines established from treated patients (Table I).

While analyzing the influence of $m y c$ family DNA amplification on patient survival, we noted the survival of small cell lung cancer patients who had cell lines established from their tumors before starting therapy was markedly shorter than nearly all series of small cell lung cancer patients reported (26-28). To determine if other poor prognostic factors previously identified at our institution (29) could explain the shortened survival in the small cell lung cancer patients who had cell lines established from their tumor before chemotherapy administration, we compared them with other comparable patients. 18 of the 19 who had cell lines established from their tumors were extensive stage patients so we compared these 19 patients to all the other extensive stage patients treated from 1977 to 1984 on the same therapeutic clinical trials who did not have cell lines established from their tumors before treatment. These 123 extensive stage small cell lung cancer patients had a median survival of $48 \mathrm{wk}$ compared with 14 wk (Fig. $4 A$ ) in the 19 patients from whom cell lines were established $(P<0.001)$. There was no marked difference between these two groups' characteristics with no sta- 

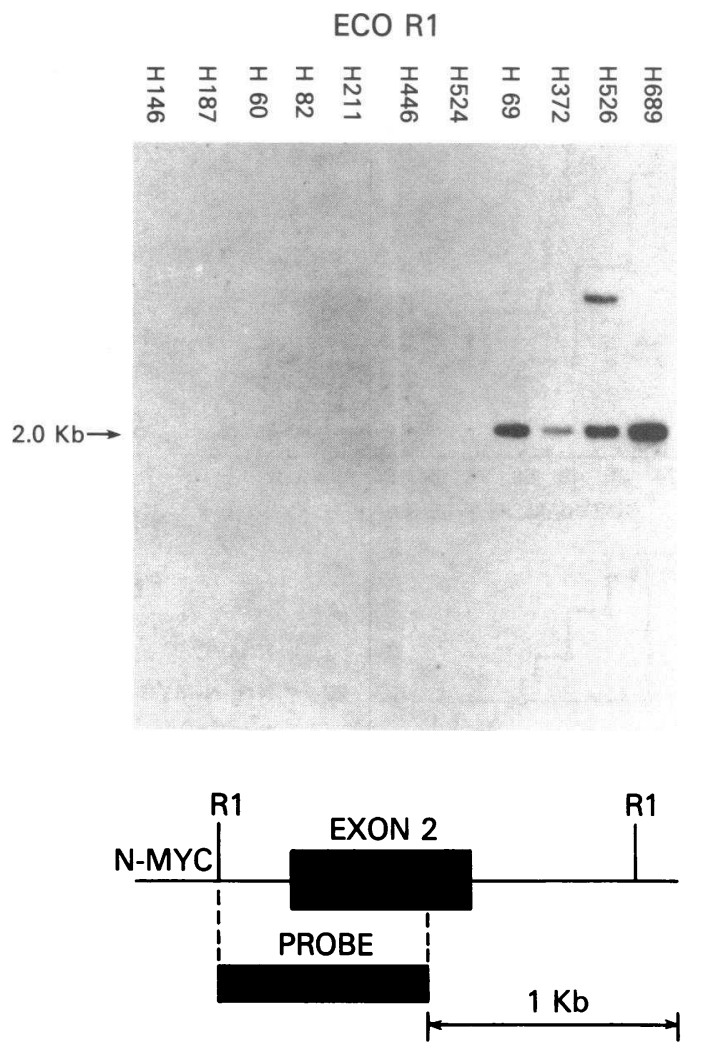

Figure 2. Autoradiogram of DNA from small cell lung cancer cell lines hybridized to an $\mathrm{N}-m y c$ probe. The same amounts of DNA per sample were used as in Fig. 1 and hybridized to the $\mathrm{Nb}-1 \mathrm{~N}-m y c$ probe (8). A schematic representation of the normal germline locus of $\mathrm{N}-m y c$ is depicted at bottom. The numbered solid box represents the second coding mRNA exon. The solid box below labeled probe represents the $\mathrm{Nb}-1$ fragment (8). Four cell lines have DNA that is amplified greater than fourfold for the N-myc oncogene that appears as a 2kb Eco RI fragment (H69, H372, H526, and H689). One, H526, is from an untreated patient and the other three, $\mathrm{H} 69, \mathrm{H} 372$, and $\mathrm{H} 689$, were established from treated small cell lung cancer patients. Additional fragments other than the 2-kb N-myc fragment appear and are thought to be rearrangements of $\mathrm{N}-m y c$ with amplification.

tistically significant imbalance at the $P \leq 0.05$ level in age $(0.22)$, sex (0.22), Zubrod performance status (0.074), number of extensive stage sites $(0.72)$, presence of liver metastasis $(0.38)$, or brain metastasis (0.37). However, one must recognize the number of patients available for analysis provides a low statistical power for detecting group differences of moderate magnitude. In addition, poor performance status was more common in patients from whom cell lines were established before treatment than in the other 123 extensive stage patients and approached standard statistical significance $(P=0.074)$. Thus poorer performance status may explain part of the shortened survival observed in the patients with cell lines established.

Decreased survival from the initiation of chemotherapy was also noted in patients who had cell lines established before chemotherapy treatment compared with patients who had cell lines established at the time of tumor relapse following chemotherapy administration (Fig. $4 B ; P<0.001$ ). This marked difference in survival between these two groups of patients can be explained in part because 8 of $25(32 \%)$ of the patients who had tumor cell lines established at the time of relapse initially had limited

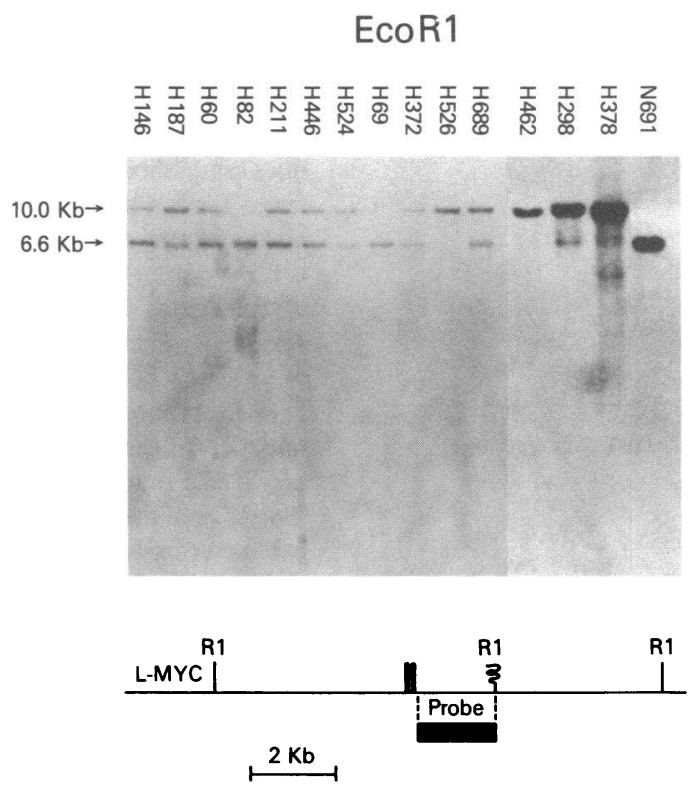

Figure 3. Autoradiograms of DNA from small cell lung cancer cell lines hybridized to an L-myc probe. The same amounts of DNA per sample were used as in Figs. 1 and 2 and hybridized to a Sma I-Eco RI L-myc probe (14). A schematic representation of the normal germline locus of L-myc is depicted at bottom. The vertical bars represent the regions of L-myc that share DNA sequence homology with c-myc and $\mathrm{N}-m y c$. Wavey line represents an Eco RI restriction fragment polymorphism site (14). Box below represents the L-myc probe. Four cell lines have DNA amplified for L-myc (H298, H378, H462, and N691), which appears at either 10-kb or 6.6-kb because of an Eco RI restriction fragment polymorphism. H462 was established from an untreated small cell lung cancer patient and the other three from treated patients (H298, H378, and N691).

stage disease compared with 1 of $19(5 \%)$ of the patients who had tumor cell lines started at the time of diagnosis. Limited stage disease is associated with prolonged survival in small cell lung cancer (26-28). In addition, the 25 patients whose tumor cell lines were established at the time of their relapse had a more favorable initial response to chemotherapy than the initial response of patients who had tumor cell lines started before the initiation of chemotherapy: 8 complete responses (32\%) vs. 1 complete response (5\%). A complete response to chemotherapy is also associated with prolonged survival in this tumor $(26,27)$.

The survival of the treated small cell lung cancer patients from whom tumor cell lines were established was correlated with the myc family DNA amplification status (Fig. 5, $A-C$ ). Chemotherapy-treated small cell lung cancer patients whose cell lines

Table I. Amplification of c-myc, N-myc, and L-myc in Small Cell Lung Cancer Cell Lines

\begin{tabular}{lccc}
\hline Amplification & $\begin{array}{l}\text { Treated } \\
\text { patients }\end{array}$ & $\begin{array}{l}\text { Untreated } \\
\text { patients }\end{array}$ & $P$ Value \\
\hline $\mathrm{n}$ & 25 & 19 & \\
c-myc & $5(20 \%)$ & $0(0 \%)$ & \\
N-myc & $3(12 \%)$ & $1(5 \%)$ & \\
L-myc & $3(12 \%)$ & $1(5 \%)$ & \\
Any $m y c$ family amplification & $11(44 \%)$ & $2(11 \%)$ & 0.04 \\
No $m y c$ family amplification & $14(56 \%)$ & $17(89 \%)$ & 0.04 \\
& & & \\
\hline
\end{tabular}



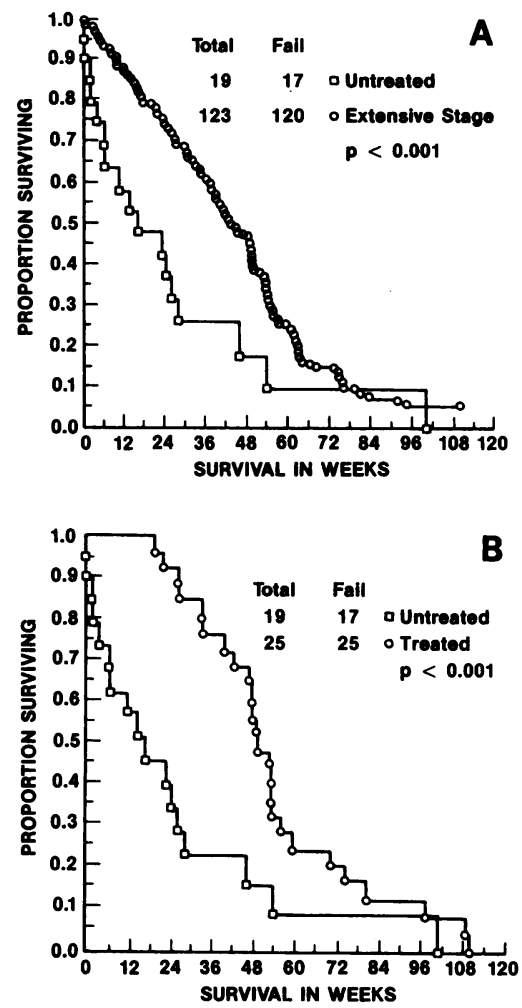

B

\section{shorter time than com-} parable extensive stage patients $(P<0.001)$. (B) The patients whose cell lines were established before the initiation of chemotherapy lived a much shorter time than the patients whose cell lines were started during tumor progression after initially responding to chemotherapy $(P<0.001)$.

had c-myc DNA amplification survived a shorter time than patients whose cell lines did not have c-myc DNA amplification (median 33 vs. $53 \mathrm{wk} ; P=0.04$ ). The prognostic factors of small cell lung cancer patients whose cell lines have c-myc amplification were compared with patients whose cell lines have a diploid copy of c-myc. No statistically significant imbalance at the $P$ $\leq 0.05$ level in age (0.45), sex (0.50), Zubrod performance status (0.73), number of extensive stage sites $(0.72)$, or the presence of liver metastasis (1.0) was observed. No patient in either group had brain metastasis. In addition, there was no statistically significant imbalance at the $P<0.05$ level between the two groups in the treatment variables of number of drugs administered $(0.50)$, months of chemotherapy treatment $(0.37)$, and the proportion of complete and partial responses to therapy (1.0). Therefore, in these previously treated small cell lung cancer patients whose cell lines were started from progressive tumors, a shortened survival not easily explained by previously identified prognostic factors or treatment variables is associated with cmyc amplification.

Shorter survival was not observed in small cell lung cancer patients whose cell lines established at the time of relapse had $\mathrm{N}-m y c$ or L-myc DNA amplification compared with patients whose cell lines were not amplified for these genes (Fig. 5, B and $C)$ although the number of patients available for analysis is small.

\section{Discussion}

In our series of small cell lung cancer patients, $m y c$ family DNA amplification was more common in cell lines established from treated rather than untreated patients. Recently investigators have studied oncogene amplification including c-myc and $\mathrm{N}$ $m y c$ in human cancer and its relationship to the clinical presentation and course of the patients $(10,11,30,31)$. Yokota et al. (30) have identified c-myc DNA amplification in 10 of 80 (13\%) human carcinoma and sarcoma fresh tumor specimens. They

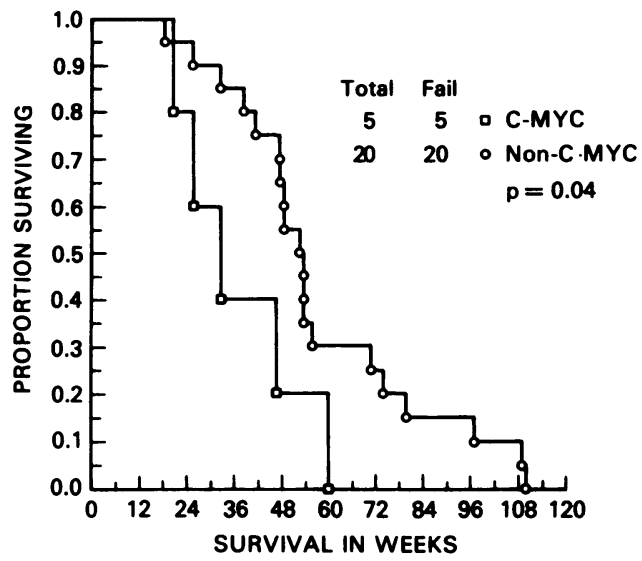

A
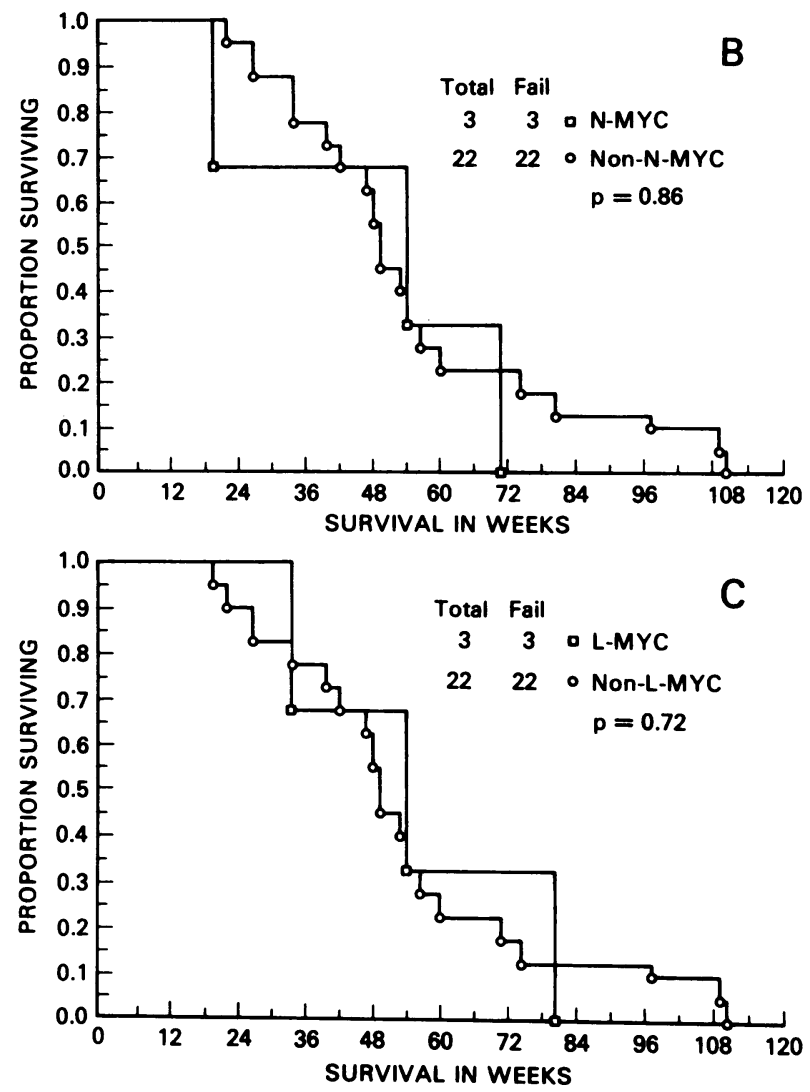

Figure 5. Survival from the initiation of chemotherapy of small cell lung cancer patients whose cell lines established at relapse had myc family DNA amplification compared with patients whose cell lines did not. $(A)$ Patients whose cell lines had DNA amplification of $c-m y c$ lived a shorter time than patients whose did not $(P=0.04)$. $(B) \mathrm{Pa}$ tients whose cell lines had DNA amplification of N-myc lived a similar period of time as those who did not $(P=0.86)$. (C) Patients whose cell lines had DNA amplification of L-myc lived a similar period of time as those whose did not $(P=0.72)$.

reported the c-myc DNA amplification was more commonly found in the more aggressive and disseminated primary tumors. In addition, Wong et al. have studied DNA extracted from paraffin-embedded small cell lung cancer specimens and found greater than threefold DNA amplification of $c-m y c$ or N-myc in 5 of 41 (12\%) tissue specimens. Neither of these groups documented the treatment status of the patients from whom the specimens were obtained. Our findings of $m y c$ family DNA amplification in $11 \%$ of cell lines established from untreated patients 
is in accordance with their findings of amplification in $13 \%$ and $12 \%$ of tumor specimens respectively. However, in the present study when the cell lines derived from chemotherapy-treated small cell lung cancer patients tumors were studied, 11 of 25 (44\%) had DNA amplification of one of the myc gene family. To our knowledge, this is the first study of tumor cell lines established from a defined clinical cohort of patients to demonstrate increased frequency of oncogene amplification associated with tumor relapse.

The small cell lung cancer patients who had cell lines established before chemotherapy treatment had markedly shortened survival compared with similar patients treated with the same chemotherapy regimens who did not have cell lines established and other comparable large series of extensive stage small cell lung cancer patients (26-28). Thus small cell lung cancer cell lines established from untreated patients may not be representative of the broad spectrum of this human cancer but may be more likely to start from patients with aggressive tumors.

In childhood neuroblastoma, this also appears to be true. DNA from 33\% of tumors from children with neuroblastoma is amplified for $\mathrm{N}-m y c$ and patients with $\mathrm{N}-m y c$ amplified tumors are more likely to present with advanced stage disease and have a more rapid tumor progression than patients whose tumors do not have N-myc DNA amplification $(10,11)$. Whereas only the $33 \%$ of neuroblastoma patients with more aggressive disease have $\mathrm{N}-m y c$ DNA amplification in their tumor, nearly all neuroblastoma cell lines examined have $\mathrm{N}-m y c$ DNA amplification. In addition, prospective studies in childhood neuroblastoma show patients whose tumors grow in culture survive significantly shorter than patients whose tumor doesn't grow (32). The persistent $\mathrm{N}-m y c$ DNA amplification in neuroblastoma cell lines and the poorer prognosis of neuroblastoma patients whose tumors develop into continuous cell lines suggest a process of selection of more biologically aggressive phenotypes in cell culture conditions.

The evidence presented here from the study of tumor cell lines from untreated small cell lung cancer patients and the previously reported studies of childhood neuroblastoma suggest that cell lines are established from groups of patients whose tumors may represent a more virulent subset of cancer. This may have important implications when adapting findings from cell line studies to the clinical treatment of cancer. Certainly this phenomena deserves further study.

Small cell lung cancer patients whose tumor cell lines were established at the time of relapse lived a shorter period of time if their cell lines had c-myc DNA amplification compared with patients with unamplified cell lines. This shortened survival seen with c-myc DNA amplification in small cell lung cancer patients is analogous to the association of $\mathrm{N}-m y c$ oncogene amplification in childhood neuroblastoma being associated with more rapid tumor progression (11). In addition to this clinical association of shortened survival observed in small cell lung cancer patients whose cell lines have c-myc DNA amplification, in vitro studies demonstrate an association of c-myc amplification with a more virulent "variant" form of small cell lung cancer cell line (16). Compared with unamplified c-myc tumor cell lines that do not express c-myc mRNA, c-myc-amplified cell lines that express $c-m y c$ mRNA tend to have altered large cell morphology in cell culture and nude mouse xenografts, shorter doubling times, higher cloning efficiency, and loss of neuroendocrine markers (16). Additional studies have shown that c-myc transfection and expression into a nonexpressing cell line results in an altered morphology in cell culture and nude mouse xenotransplants, a more rapid growth rate, and a higher cloning efficiency than the original cloned diploid c-myc cell line (33). This in vitro data plus the observation that c-myc DNA amplification appears to be associated with more rapid tumor progression and shortened patient survival supports that the oncogene c-myc plays an important role in the biology of small cell lung cancer.

$m y c$ family DNA amplification is present in small cell lung cancer tumors and does not only occur in cell culture. The myc family DNA copy number in the cell lines and tumors from the same patient have been identical in all seven sets studied (34). In both instances where a tumor cell line had $m y c$ family DNA amplification and tumor tissue from the same individual was available for study, the tumor tissue had DNA amplification to a similar degree (13). In addition, five additional cell lines and tumors from the same small cell lung cancer patient did not have DNA amplification of any $m y c$ family gene. There have been no examples identified to date of discordance between myc family gene copy number in the tumor cell line and corresponding tumor specimen from the same patient.

Amplification does not appear to be associated with the duration of exposure to the mutagenic properties of chemotherapy. The patients' tumor cells that gave rise to c-myc-amplified cell lines were actually exposed in vivo to chemotherapy for a shorter period of time than the tumor cells that gave rise to the nonamplified cell lines (median of 7 mo vs. $10 \mathrm{mo}$ ). In addition, the amplification of c-myc does not appear to be only an event that occurs shortly before the patients' deaths. The time between obtaining tumor specimens that gave rise to cell lines and death was similar for patients with both amplified and nonamplified tumor cell lines (median, 3 wk vs. 5 wk, respectively). This suggests that the shortened survival in previously treated patients whose tumors gave rise to cell lines with c-myc amplification is due to more rapid clinical disease progression from the start of chemotherapy than in their unamplified counterparts.

Small cell lung cancer regresses after chemotherapy administration in the majority of cases but subsequent regrowth of tumor usually occurs (29). We cannot definitely determine if administration of chemotherapy kills sensitive nonamplified cells and selects resistant DNA-amplified tumor cells or if the drugs induce further mutation and amplification. Studies employing in situ hybridization of tumor specimens from untreated small cell lung cancer patients to attempt to identify whether subpopulations of cells express $m y c$ family oncogenes may help to clarify this issue.

In summary, gene amplification of the $m y c$ family of oncogenes is more common in small cell lung cancer cell lines established from patients following administration of chemotherapy and subsequent tumor progression than in cell lines established from untreated patients. The ability to start a cell line from an untreated small cell lung cancer patient is associated with a shortened survival, although any etiologic relationship between these observations is far from proven. In addition, amplification of $c-m y c$, an oncogene whose expression is related to more rapid growth in cell culture studies, is associated with a shortened survival in small cell lung cancer patients. Prospective studies of additional cell lines and patients are required before it is possible to determine with a higher degree of certainty whether c-myc amplification is independent of other previously identified prognostic factors for survival. Further definition of these issues is important for our clinical understanding of the role of oncogenes in the generation of human malignancy. 


\section{References}

1. Collins, S., and M. Groudine. 1982. Amplification of endogenous myc-related DNA sequences in a human myeloid leukaemia cell line. Nature (Lond.). 298:679-681.

2. Alitalo, K., M. Schwab, C. C. Lin, H. E. Varmus, and J. M. Bishop. 1983. Homogeneously staining chromosomal regions contain amplified copies of an abundantly expressed cellular oncogene (c-myc) in malignant neuroendocrine cells from a human colon carcinoma. Proc. Natl. Acad. Sci. USA. 80:1707-1711.

3. Kozbor, D., and C. M. Croce. 1984. Amplification of the c-myc oncogene in one of five human breast carcinoma cell lines. Cancer Res. 44:438-441.

4. Nakasato, F., H. Sakamoto, M. Mori, K. Hayashi, Y. Shimosato, M. Nishi, S. Takao, K. Nakatani, M. Terada, and T. Sugimura. 1984. Amplification of the c-myc oncogene in human stomach cancers. Gann. 75:737-742.

5. Trent, J., P. Meltzer, M. Rosenblum, G. Harsh, K. Kinzler, R. Mashal, A. Feinberg, and B. Vogelstein. 1986. Evidence for rearrangement, amplification, and expression of c-myc in a human glioblastoma. Proc. Natl. Acad. Sci. USA. 83:470-473.

6. Little, C. D., M. M. Nau, D. N. Carney, A. F. Gazdar, and J. D. Minna. 1983. Amplification and expression of the c-myc oncogene in human lung cancer cell lines. Nature (Lond.). 306:194-196.

7. Saksela, K., J. Bergh, V. P. Lehto, K. Nilsson, and K. Alitalo. 1985. Amplifications of the c-myc oncogene in a subpopulation of human small cell lung cancer. Cancer Res. 45:1823-1827.

8. Schwab, M., K. Alitalo, K. H. Klempnauer, H. E. Varmus, J. M. Bishop, F. Gilbert, G. Brodeur, M. Goldstein, and J. Trent. 1983. Amplified DNA with limited homology to myc cellular oncogene is shared by human neuroblastoma cell lines and a neuroblastoma tumor. Nature (Lond.). 305:245-248.

9. Kohl, N. E., N. Kanda, R. R. Schreck, G. Bruns, S. A. Latt, F. Gilbert, and F. W. Alt. 1983. Transposition and amplification of oncogene-related sequences in human neuroblastomas. Cell. 35:359-367.

10. Brodeur, G. M., R. C. Seeger, M. Schwab, H. E. Varmus, and J. M. Bishop. 1984. Amplification of N-myc in untreated human neuroblastomas correlates with advanced disease stage. Science (Wash. DC). 224:1121-1124.

11. Seeger, R. C., G. M. Brodeur, H. Sather, A. Dalton, S. E. Siegel, K. Y. Wong, and D. Hammond. 1985. Association of multiple copies of the $\mathrm{N}-m y c$ oncogene with rapid progression of neuroblastomas. $N$. Engl. J. Med. 313:1111-1116.

12. Lee, W. H., A. L. Murphree, and W. F. Benedict. 1984. Expression and amplification of the $\mathrm{N}-m y c$ gene in primary retinoblastoma. Nature (Lond.). 309:458-460.

13. Nau, M. M., B. J. Brooks, D. N. Carney, A. F. Gazdar, J. F. Battey, E. A. Sausville, and J. D. Minna. 1986. Human small-cell lung cancer shows amplification and expression of the N-myc gene. Proc. Natl. Acad. Sci. USA. 83:1092-1096.

14. Nau, M. M., B. J. Brooks, J. Battey, E. Sausville, A. F. Gazdar, I. R. Kirsch, O. W. McBride, V. Bertness, G. F. Hollis, and J. D. Minna. 1985. L-myc, a new $m y c$-related gene amplified and expressed in human small small cell lung cancer. Nature (Lond.). 318:69-73.

15. Carney, D. N., A. F. Gazdar, G. Bepler, J. G. Guccion, P. J. Marangos, T. W. Moody, M. H. Zweig, and J. D. Minna. 1985. Establishment and identification of small cell lung cancer cell lines having classic and variant features. Cancer Res. 45:2913-2923.

16. Gazdar, A. F., D. N. Carney, M. M. Nau, and J. D. Minna. 1985. Characterization of variant subclasses of cell lines derived from small cell lung cancer having distinctive biochemical, morphological, and growth properties. Cancer Res. 45:2924-2930.

17. Zubrod, C. G., M. Schneiderman, E. Frei III, C. Brindley, G. L. Gold, B. Shnider, R. Oviedo, J. Gorman, R. Jones, Jr., U. Jonsson, J. Colsky, T. Chalmers, B. Ferguson, M. Dederick, J. Holland, O. Selawry, W. Regelson, L. Lasagna, and A. H. Owens, Jr. 1960. Appraisal of methods for the study of chemotherapy of cancer in man: comparative ther- apeutic trials of nitrogen mustard and triethylene thiophosphoramide. J. Chronic Dis. 11:7-33.

18. Johnson, B. E., D. C. Ihde, P. A. Bunn, B. Becker, T. Walsh, Z. Weinstein, M. J. Matthews, J. Whang-Peng, R. W. Makuch, A. JohnstonEarly, A. S. Lichter, D. N. Carney, M. H. Cohen, E. Glatstein, and J. D. Minna. 1985. Patients with small-cell lung cancer treated with combination chemotherapy with or without irradiation. Ann. Intern. Med. 103:430-438.

19. Hieter, P. A., G. F. Hollis, S. J. Korsmeyer, T. A. Waldman, and P. Leder. 1981. Clustered arrangement of immunoglobulin lambda constant region genes in man. Nature (Lond.). 294:536-540.

20. Southern, E. M. 1975. Detection of specific sequences among DNA fragments separated by gel electrophoresis. J. Mol. Biol. 98:503517.

21. Battey, J., C. Moulding, R. Taub, W. Murphy, T. Stewart, H. Potter, G. Lenoir, and P. Leder. 1983. The human c-myc oncogene: structural consequences of translocation in the IgH locus in Burkitt lymphoma. Cell. 34:779-787.

22. Sausville, E., D. Carney, and J. Battey. 1985. The human vasopressin gene is linked to the oxytocin gene and is selectively expressed in a cultured lung cancer cell line. J. Biol. Chem. 260:10236-10241.

23. Kaplan, E. L., and P. Meier. 1958. Non-parametric estimation from incomplete observations. J. Am. Stat. Assoc. 53:457-481.

24. Gehan, E. A. 1965. A generalized Wilcoxon test for comparing arbitrarily singly-censored samples. Biometrika. 52:203-224.

25. Whang-Peng, J., P. A. Bunn, Jr., C. S. Kao-Shan, E. C. Lee, D. N. Carney, A. Gazdar, and J. D. Minna. 1982. A nonrandom chromosomal abnormality, del 3p(14-23), in human small cell lung cancer (SCLC). Cancer Genet. Cytogenet. 6:119-134.

26. Cohen, M. H., D. C. Ihde, P. A. Bunn, B. E. Fossieck, M. J. Matthews, S. E. Shackney, A. Johnston-Early, R. Makuch, and J. D. Minna. 1979. Cyclic alternating combination chemotherapy for small cell bronchogenic carcinoma. Cancer Treat. Rep. 63:163-170.

27. Livingston, R. B., T. N. Moore, L. Heilbrun, R. Bottomley, D. Lehane, S. E. Rivkin, and T. Thigpen. 1978. Small-cell carcinoma of the lung: combined chemotherapy and radiation. Ann. Intern. Med. 88: 194-199.

28. Morstyn, G., D. C. Ihde, A. S. Lichter, P. A. Bunn, D. N. Carney, E. Glatstein, and J. D. Minna. 1984. Small cell lung cancer 1973-1983: Early progress and recent obstacles. Int. J. Radiat. Oncol. Biol. Phys. 10:515-539.

29. Ihde, D. C., R. W. Makuch, D. N. Carney, P. A. Bunn, M. H. Cohen, M. J. Matthews, and J. D. Minna. 1981. Prognostic implications of stage of disease and sites of metastases in patients with small cell carcinoma of the lung treated with intensive combination chemotherapy. Am. Rev. Respir. Dis. 123:500-507.

30. Yokota, J., Y. Tsunetsugu-Yokota, H. Battifora, C. Le Fevre, and M. J. Cline. 1986. Alterations of $m y c, m y b$, and $r a s^{\mathrm{Ha}}$ proto-oncogenes in cancers are frequent and show clinical correlation. Science (Wash. DC). 231:261-265.

31. Wong, A. J., J. M. Ruppert, J. Eggleston, S. R. Hamilton, S. B. Baylin, and B. Vogelstein. 1986. Gene amplification of c-myc and Nmyc in small cell carcinoma of the lung. Science (Wash. DC). 233:461464.

32. Reynolds, C. P., E. P. Frenkel, and R. G. Smith. 1980. Growth characteristics of neuroblastoma in vitro correlate with patient survival. Trans. Assoc. Am. Physicians. 93:203-211.

33. Johnson, B. E., J. Battey, I. Linnoila, K. L. Becker, R. W. Makuch, R. H. Snider, D. N. Carney, and J. D. Minna. 1986. Changes in the phenotype of human small cell lung cancer cell lines after transfection and expression of the c-myc proto-oncogene. J. Clin. Invest. 78:525532.

34. Johnson, B. E., M. Nau, A. F. Gazdar, A. Simmons, A. Cashell, M. J. Matthews, and J. Minna. 1986. Amplification of myc oncogenes is less common in small cell lung cancer patients tumors than in small cell lung cancer cell lines. Proc. Am. Soc. Clin. Oncol. Annu. Meet. 4: 16. (Abstr.) 